\title{
Original $\mid$ PRIMARY MEDIASTINAL B-CELL LYMPHOMA TREATMENT OUTCOME OF Article 36 PATIENTS
}

\author{
Mahmoud Abdelsalam \\ ${ }^{1}$ King Faisal Specialist Hospital and Research Center, Cancer Center, Medical Oncology Unit. \\ ${ }^{2}$ Kasr El-Aini Center for Clinical Oncology, Faculty of Medicine Cairo University.
}

\begin{abstract}
Introduction: Primary mediastinal B-cell lymphoma (PMBCL) is a distinct clinicopathological entity of large B-cell lymphoma. The optimal treatment is not clear yet, with some studies demonstrated favourable outcome compared to other types of diffuse large B-cell lymphoma.

Aim of the Work: The purpose of this retrospective study is to evaluate the clinical characteristics, primary presentation, treatment given, response to treatment and outcome in Saudi patients.

Materials and Methods: All patients with PMBCL diagnosed and treated during period 19952006- were identified at Oncology Data Unit, King Faisal Specialist Hospital. Patient's characteristics, prognostic factors, details of treatment and outcome were reviewed. Thirty-six patients were identified, all of them received CHOP regimen of chemotherapy which was followed by radiation therapy in 31 patients.

Result: Median age was 31.5 years (range 1866-). Forty four percent $(n=16)$ had ECOG performance status of $>2$. There were 21 (58.4\%) females and 15(41.6\%) males with a female predominance. Complete response rate (CR+CRu) was $77.8 \%$. Median follow was 57.16 months (+/-12.2m); the median overall survival (OS) and event free survival were not reached. Univariate analysis revealed that female gender was the only prognostic factor with higher OS and EFS, while no other factor have impact on survival in multivariate analysis.

Conclusion: This retrospective study supports other similar studies which revealed a strong prevalence of females over males and favourable outcome in PMBCL.
\end{abstract}

Key Words: Primary, mediastinal, B-Cell, lymphoma, treatment, outcome.

Corresponding Author: Email: mahmoudabdelsalam@hotmail.com, mabdelsalam@kfshrc.edu.sa

\section{INTRODUCTION}

Until 20 years ago, primary mediastinal B-cell lymphoma (PMBCL) was an unrecognized entity. Lichtenstein et al. ${ }^{1}$ first described a distinct subset of young adult lymphoma Patients. However, it was not until the thymus was no longer considered to be exclusively a T-cell organ and a B-cell population was surprisingly identified in normal human thymic medulla. Then the unique clinical and biologic features of this entity were described ${ }^{1,2}$. Primary mediastinal lymphoma is a tumor that originates from the thymus, initially grows in the mediastinum, often to a large size, follows a pattern of extra-nodal tropism with a propensity to invade local extra-nodal structures and readily spreads to distinct extra-nodal sites following a unique biology ${ }^{3}$. It comprises 7 percent of diffuse large B-cell lymphoma (DLBCL) and 2.4 percent of all non-Hodgkin's lymphoma (NHL) ${ }^{4}$. There is slight female predominance and median age of fourth decade $^{4}$. Distinct chromosomal aberration have been observed including consistent gains in chromosome $9 p$ and $2 p$ corresponding to the JAK2 and cREL loci, respectively ${ }^{5,6}$.
Despite these clear clinical and pathological features there is imprecision in the diagnosis of PMBCL. This diagnostic uncertainty can influence reports on biological characteristics and survival analysis, complicating comparisons between studies. Thus there have been varied reports regarding survival in PMBCL, in part due to the difficulty in separating PMBCL from DLBCL with secondary mediastinal or hilar involvement. This problem is highlighted in earlier studies where a more aggressive course was observed ${ }^{7-11}$ with cure rates similar to DLBCL despite the younger age of presentation. In contrast, more recent analysis have suggested survival pattern equivalent or in some cases superior to DLBCL $^{4,12-14}$.

Recent microarray studies revealed a unique molecular signature of PMBCL distinguishing it from DLBCL, with striking overlap with the nodular sclerosis subtype of classical Hodgkin's lymphoma (NS cHL) ${ }^{15-17}$ and provide insight into potential useful diagnostic markers ${ }^{17}$. Survival comparisons of PMBCL defined by gene expression signature support the notion that PMBCL may have a different natural history from DLBCL ${ }^{17}$. 
The goal of this retrospective analysis was to look for patient characteristics and type of treatment and to evaluate the outcome of treatment including, response rate (RR), event free survival (EFS) and overall survival (OS).

\section{MATERIALS AND METHODS}

This is a hospital-based retrospective analysis with the primary aim to identify all patients with PMBCL diagnosed and treated at King Faisal Specialist Hospital and Research Center (KFSHRC) in the period 19952006. The computerized oncology data unit (ODU) in KFSHRC containing all patients treated since January 1995, was searched and medical records were reviewed to identify those patients presenting with a prominent mediastinal mass and considered to be PMBCL based on the current REAL/WHO classification ${ }^{18,}{ }^{19}$. Patients with minimal mediastinal involvement as part of more extensive lymphoma elsewhere were excluded. To ensure adequate follow-up for outcome analysis only those patients diagnosed before $31^{\text {st }}$ December 2006 were included. In total, 36 patients were identified. The histologic diagnosis was made according to criteria previously described: Diffuse proliferation of large, somewhat polymorphous cells resembling centroblasts; large centrocytes and less often immunoblasts with pale clear cytoplasm lacking a follicular pattern, the constant presence of thin-band compartmentalizing sclerosis and occasionally thymic remnants. A B-cell phenotype was demonstrated by immunohistochemical studies ${ }^{20-22}$. Old cases, before 2000, were reviewed again to assure the diagnosis of PMBCL. The diagnostic material was obtained through thoracotomy/mediastinoscopy in most patients and lymph node biopsy in some cases.

Patients were clinically staged according to Ann Arbor classification on the basis of physical examination, routine laboratory tests, bone marrow aspirate and trephine biopsy, chest radiography and computed tomographic scans of the chest, abdomen and pelvis. Bulky disease was defined as a mediastinal mass measuring two thirds or more of the intra-thoracic diameter at the level of T1o.

All patients received CHOP chemotherapy (CT) regimen including, cyclophosphamide $750 \mathrm{mg} / \mathrm{m}^{2}$ on day 1 , adriamycine $50 \mathrm{mg} / \mathrm{m}^{2}$ on day 1 , vencristin $1.4 \mathrm{mg} / \mathrm{m}^{2}$ on day (maximum $2 \mathrm{mg}$ ) and prednisone 50mg twice daily for 5 days, 6 (16.7\%) patients received retuximab $375 \mathrm{mg} / \mathrm{m}^{2}$ on day 1 , in addition. Thirty one patients also received radiotherapy (RT) to the site of mediastinal residual disease (14 patients) or as consolidation (9 patients). The radiation was given in 2 parallel opposed fields using 6-10 MV linear accelerator machine in a dose range between 36Gy to 45GY (18Gy to 20GY daily, 5 days weekly). Doses were calculated at mid point of separation of fields. Radiation was started in 3-4 weeks after the end of chemotherapy. Data on age, sex, performance status at diagnosis, LDH, stage, B-symptoms, number of extra-nodal disease, size of the disease, response to treatment and follow-up were collected.

\section{Statistical Analysis:}

All statistics were performed with SPSS software (statistical package for social science, version 11). Description statistics was presented as number and percentage (frequency distribution). Fisher's exact test was used to compare the results for significance with p value of $<0.05$ was considered as significant results. A complete response (CR) was defined as disappearance of all evidence of tumor and with the patient free of all disease related symptoms. A partial response was defined as a $>50 \%$ reduction in the sum of the products of the diameters of all measurable lesions, without increase in size or new lesions appearing. Stable disease (SD) was defined as no change or $<25 \%$ in the sum of the products of the diameters of any measurable lesions. Progressive disease (PD) was defined as an increase of $>25 \%$ in the sum of the products of the diameters of any measurable disease or unequivocal appearance of new lesions. Over all survival (OS) was defined as time from date of diagnosis to date of last follow up or death. Event free survival (EFS) was defined as time from date of diagnosis to date of initiation of additional treatment or relapse, where, residual disease after treatment, time to change in treatment or death was considered to be events. Time to progression (TTP) is defined as time from date of achieving CR or PR to date of recurrence or distant metastasis. Cox regression analysis was used for univarieate and multivariate analysis of factors affecting survival, with a p-value of $<0.05$ was used for significance. The Kaplan-Meire method was used to determine survival curves and the log-rank test was used to compare survival in different populations, $\mathrm{P}$ value was used with a significance of $<0.05$.

\section{RESULTS}

Selected patients and clinical characteristics at presentation are summarized in Table 1 . The median age was 31.5 years (+/-13) (range 18-66 years); 21 patients (5.4\%) were female and15 (41.6\%) were male. Most of our cases presented with symptoms and signs in the clinical context of rapidly enlarging, mediastinal mass as 31 patients out of 36 (86.1\%) had a bulky disease on presentation. This was associated with superior vena caval syndrome in only 6 patients (16.7\%), pericardial effusion in 3 patients (8.3\%) and pleural effusion in 5 patients (13.9\%). Nineteen patients (52.7\%) had constitutional symptoms. LDH was normal in 11 patients (30.6\%). The majority of our patients (31 patients $(86.1 \%)$ ) presented in early stages (stage I and II) while 5 patients (13.9\%) had advanced stages. Less than two thirds of our patient cohort had ECOG PS 0-1 (55.6\%). The international prognostic index (crude IPI) assessment revealed that 5 patients only had high-intermediate and high index (3-4) while all other patients were assessed from 0-2 (low and low-intermediate). Five patients (13.9\%) had extranodal 
disease. All our patients received CHOP chemotherapy regimen (median number of cycles was 6 with a range of 3-8 cycles), this was associated with retuximab in 6 patients while one patient who was elderly didn't tolerate the first cycle of CHOP and he was shifted to CVP. Twenty three patients had RT after chemotherapy.

Table 1: Patients Characteristics (36 Patients).

\begin{tabular}{|c|c|c|c|}
\hline Factor & & No. & $\%$ \\
\hline \multicolumn{4}{|l|}{ Age (year) } \\
\hline & Median & $31.5(+/-13)$ & \\
\hline & Range & $18-66$ & \\
\hline \multicolumn{4}{|l|}{ Gender } \\
\hline & Male & 15 & 41.6 \\
\hline & Female & 21 & 58.4 \\
\hline B-Symptoms & & 19 & 52.7 \\
\hline \multicolumn{4}{|l|}{ PS } \\
\hline & $0-1$ & 20 & 55.6 \\
\hline & 2 & 7 & 19.4 \\
\hline & 3 & 6 & 16.7 \\
\hline & 4 & 3 & 8.3 \\
\hline \multicolumn{4}{|l|}{ LDH } \\
\hline & Normal & 11 & 30.6 \\
\hline & High & 25 & 69.4 \\
\hline \multicolumn{4}{|l|}{ IPI } \\
\hline & 0 & 8 & 22.2 \\
\hline & 1 & 12 & 33.3 \\
\hline & 2 & 11 & 30.7 \\
\hline & 3 & 3 & 8.3 \\
\hline & 4 & 2 & 5.5 \\
\hline Bulky & & 31 & 86.1 \\
\hline Extranodal & & 5 & 13.9 \\
\hline SVC & & 6 & 16.7 \\
\hline Pl. Effusion & & 5 & 13.9 \\
\hline Peric. Effusion & & 3 & 8.3 \\
\hline \multicolumn{4}{|l|}{ Stage } \\
\hline & I & 5 & 13.9 \\
\hline & II & 26 & 72.2 \\
\hline & III & 0 & 0 \\
\hline & IV & 5 & 13.9 \\
\hline \multicolumn{4}{|l|}{ Chemotherapy } \\
\hline & СHOP & 29 & 80.5 \\
\hline & R-CHOP & 6 & 16.7 \\
\hline & CHOP-CVP & 1 & 2.8 \\
\hline \multicolumn{4}{|l|}{ Treatment } \\
\hline & CT & 5 & 13.9 \\
\hline & $\mathrm{CT}+\mathrm{RT}$ & 31 & 86.1 \\
\hline
\end{tabular}

\section{Response to Treatment and Survival:}

Overall response rate (RR) after chemotherapy was 94.5\% (34 patients). 23 patients (63.9\%) achieved CR or Cru (undetermined CR) after chemotherapy alone. Twenty-eight patients (77.8\%) achieved CR or Cru after chemo-radiotherapy while 5 patients (13.9\%) had progressive disease. Out of the 11 patients who had PR after chemotherapy, 5 went to CR after radiation-therapy (Table 2).
Table 2: Response Rates (36 Patients).

\begin{tabular}{lcccc}
\hline Response & \multicolumn{2}{c}{ CT } & \multicolumn{2}{c}{ CT+RT } \\
\hline & No. & \% & No. & \% \\
\hline CR & 9 & 25 & 23 & 63.9 \\
CRu & 14 & 38.9 & 5 & 13.9 \\
PR & 11 & 30.6 & 3 & 8.3 \\
PD & 2 & 5.5 & 5 & 13.9 \\
\hline
\end{tabular}

After a median follow-up of 57.2 months (+/-12.2) (range of 11.6-116.3 months), 11 (30.6\%) had died and $13(36.2 \%)$ had at least one event. the median OS for the whole group was not reached (Figure 1) and median EFS was not reached (Figure 2). The 5-year OS was $68 \%$ and 5-year EFS was $62 \%$.

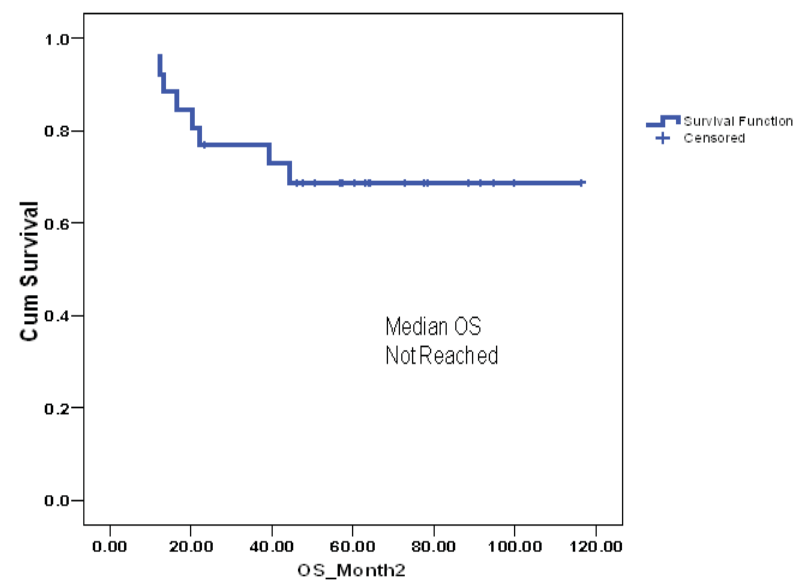

Figure 1: OS whole group (36 Patients).

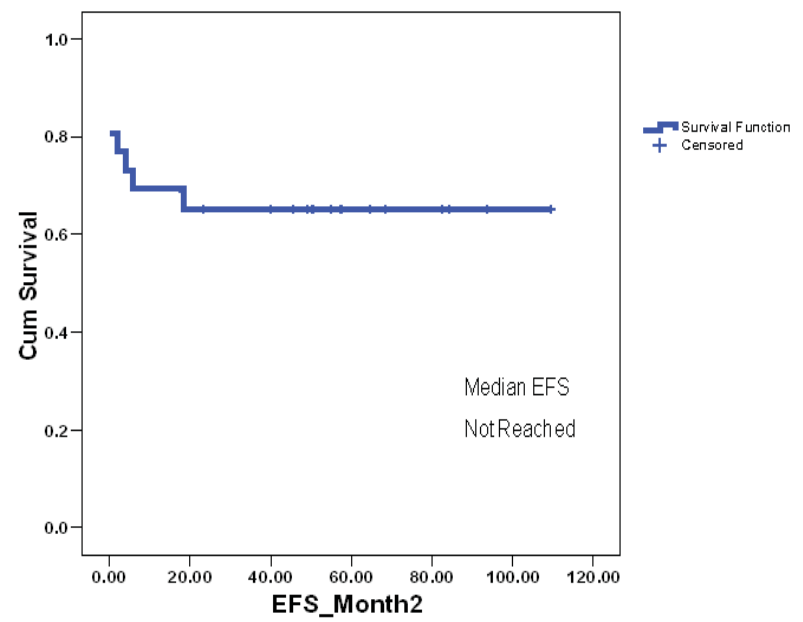

Figure 2: EFS whole group (36 Patients).

In univariate analysis of prognostic factors (including, gender stage, PS, LDH, bulky disease, B-symptoms and IPI), our results demonstrated that only females showed longer OS and EFS than males $(\mathrm{p}=0.001$ and 0.007 , respectively) (Figures 3 and 4) (Table 3). There was no significance of clinical response after chemotherapy versus that after combined treatment by chemoradiotherapy. Fluorodeoxyglucose Positron Emission Tomography $\left({ }^{18} \mathrm{FDG}-\mathrm{PET}\right)$ was performed in 9 patients who achieved PR or CRu after chemotherapy, 3 out of the 9 patients (33.3\%) were PET negative referring 
that they achieved CR after chemotherapy. There was no significance of functional response versus clinical response in this group of patients.

Table 3: Univariate Analysis of Prognostic Factors.

\begin{tabular}{lcc}
\hline Factor & EFS (P value) & OS (P value) \\
\hline Gender & 0.007 & 0.001 \\
Stage & 0.746 & 0.501 \\
PS & 0.42 & 0.214 \\
LDH & 0.50 & 0.797 \\
Bulky & 0.328 & 0,37 \\
B-symptoms & 0.559 & 0.338 \\
IPI & 0.746 & 0.501 \\
\hline
\end{tabular}

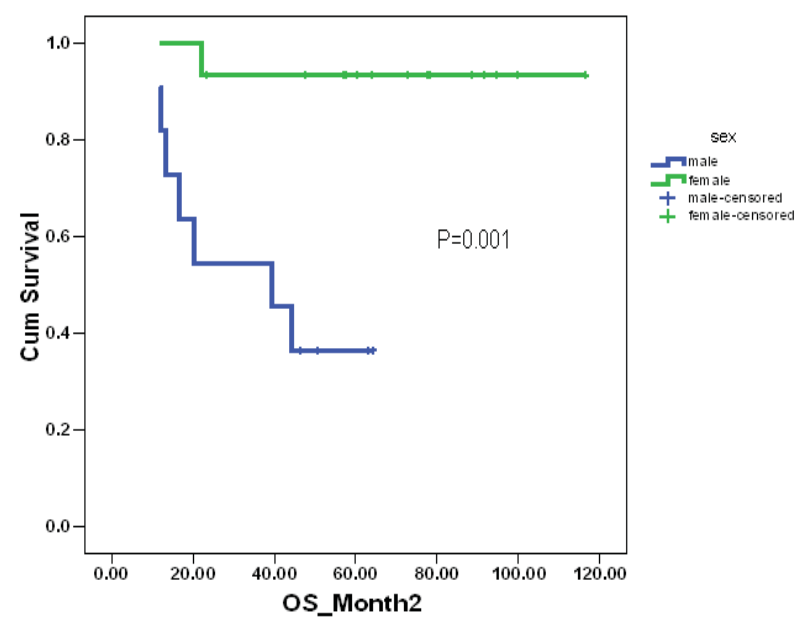

Figure 3: OS According to Gender.

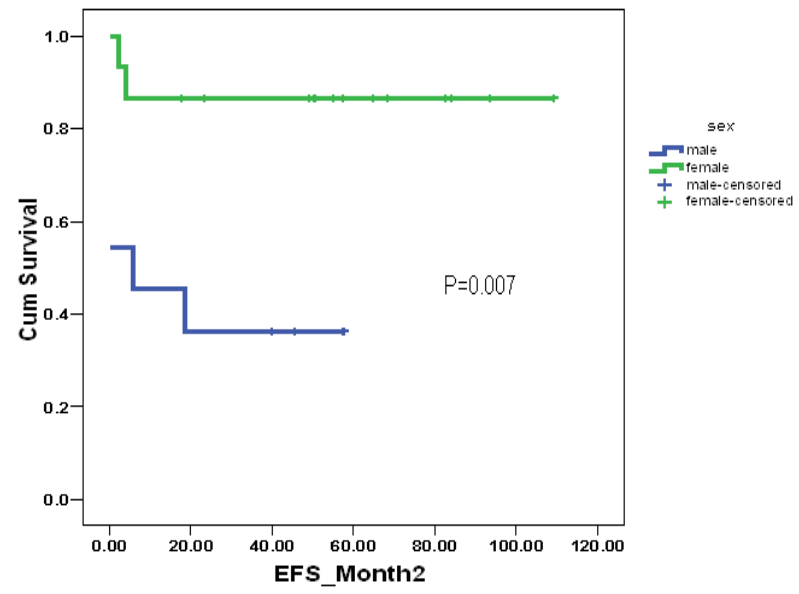

Figure 4: EFS ACcording to Gender.

A multivariate analysis didn’t reveal any significance from any of the studied prognostic factors (Table 4).

Table 4: Multivariate Analysis of Prognostic Factors.

\begin{tabular}{lcc}
\hline Factor & EFS (P value) & OS (P value) \\
\hline Gender & 0.94 & 0.235 \\
Stage & 0.860 & 0.675 \\
PS & 0.542 & 0.489 \\
LDH & 0.95 & 0.849 \\
Bulky & 0.96 & 0,97 \\
B-symptoms & 0.97 & 0.82 \\
IPI & 0.95 & 0.705 \\
\hline
\end{tabular}

\section{DISCUSSION}

The current study confirms the previous findings concerning PMBCL, which appears to have some characteristic clinical features different from those of other NHL. It is evident that there is a strong prevalence of females over males and the age at onset is younger compared with all aggressive NHL in adults. Typical features also include presentation an almost all cases with symptoms of a rapidly enlarging mediastinal mass with a high frequency of superior vena cava syndrome and extra-nodal tropism as also reported by others ${ }^{7}, 18,23,24$.

Several studies have reported CR rates of 53\% to $80 \%$ after initial therapy with intensive chemotherapy followed by RT with $50 \%$ to $85 \%$ OS after 5 years $^{7,9,10,12,13,23-28}$.

In our hospital-based cohort, 36 patients were treated by standard chemotherapy (CHOP regimen), associated with retuximab in 6 patients and one patient (who was elderly) did not tolerate the treatment, so was shifted to CVP regimen. Our CT protocol was unified in all the patients and was followed by RT in most of the patients (86.1\%). The CR rate in current trial was 63.9\% after CT and improved to $77.8 \%$ after RT. The median OS and EFS were not reached after median follow-up of 57.1 months. Current study showed a relatively high 5-year OS and EFS rates of $68 \%$ and $62 \%$, respectively which demonstrate a favorable outcome of PMBCL compared to DLBCL (using similar chemotherapy regimen). Similar results were reported by Savage et al. ${ }^{15}$. In their study they reported a significant difference in 10-year PFS (69\% versus $47 \%$; $\mathrm{P}=0.0001$ ) and 10 -year OS (66\% versus $43 \% \mathrm{P}=0.00001)$, favoring PMBCL. A retrospective study of 40 patients with stage I or II PMLBCL treated with doxorubicin-containing chemotherapy (eg, CHOP) alone (5 patients) or followed by adjuvant involved-field or modified mantle-field radiation therapy (35 patients) reported 88 percent complete remission rates with 5 -year relapse-free survival of 67 percent $^{27}$, this is more or less similar to what we are reporting now, with $77.8 \%$ CR after chemo-radiotherapy and 5 -year EFS of $62 \%$. A second retrospective analysis of 53 patients treated with MACOP-B or VACOP-B followed by involved-field radiation therapy reported a 5-year overall-survival rate of 87 percent $^{29}$. Among patients in partial remission after chemotherapy, 92 percent obtained a complete remission after radiation therapy. A retrospective study analyzed results in 138 consecutive patients with PMLBCL, 80 percent of whom had bulky mediastinal disease ${ }^{4}$. Treatment included chemotherapy with CHOP, MACOP-B, or VACOP-B with or without involved field radiation therapy. Seventysix percent of patients achieving complete remission with chemotherapy received consolidation radiation therapy. The addition of involved field RT as consolidation therapy improved event-free survival irrespective of the 
choice of chemotherapy (approximately 75 versus 90 percent at three years). A retrospective study reported outcomes in 141 patients treated with one of three strategies: CHOP, upfront autologous transplantation, or the dose-dense NHL-15 protocol consisting of induction doxorubicin plus vicristine and consolidation cyclophosphamide ${ }^{30}$. With a median follow-up of 11 years, 5-year overall survival rates were 51, 78 and 84 percent, respectively. Other studies have suggested that more aggressive regimens may be associated with better outcome ${ }^{4,14}$; however, no prospective randomized studies comparing these regimens have been performed to answer this question definitively. Savage et al. ${ }^{15}$ reported that MACOPB/VACOPB regimens were associated with superior survival rates, despite the fact that their treatment regimens were based on era-specific guidelines, there were more patients in the CHOP group with poor performance status and elevated LDH and in multivariate analysis, only a trend to improve outcome was associated with the more intensified regimens. Although Fisher et al. ${ }^{31}$ proved that results with CHOP are equivalent to results with three intensive regimens: m-BACOD, pro MACE-CytaBOM and MACOP-B for advanced lymphoma in general. In the case of PMBCL one could argue that this demonstration does not apply. Given the limitation of such historical comparisons, randomized controlled studies are necessary before recommending the intensified regimens.

Radiotherapy was given in an attempt to improve on the response achieved with CT alone or as consolidation. Because of bulkiness, consolidation RT to the mediastinum is a common practice in this type of lymphoma ${ }^{10,23,25}$. Whether there is a role and benefit of RT in the eradication of RT in the eradication of the disease, it is unclear and difficult to assess. It has been suggested that RT might be beneficial as consolidation after first remission to treatment ${ }^{23,25}$. Other studies report ineffectiveness of RT as salvage treatment in chemotherapy-resistant disease ${ }^{23,26}$. However, RT has no place as a single treatment modality, prior to treatment and it is best avoided and should be reserved as an emergency pre-diagnostic measure. In the present study the CR rate was improved from $63.9 \%$ to $77.8 \%$ we cannot compare CT versus CT followed by RT because most of our patients received RT after CT and only 5 patients (13.9\%) had CT only.

According to our results, female gender appears to be the most important prognostic factor. Female showed significantly higher OS and EFS than males in univariate analysis. However multivariate analysis did not show any significance impact from all the studied prognostic factors. The prognostic relevance of other factors (age, PS, LDH, response to treatment, IPI....) was not proved in this study. Nevertheless, other studies have defined the prognostic significance of tumor bulk, residual disease, pleural/pericardial effusion, multiple extra-nodal extensions, compromised dose intensity and incomplete response to treatment in the outcome of the disease ${ }^{10,13,23,26}$. Romaguera et al..$^{32}$ tested two prognostic models devised for intermediate grade lymphomas (the age adjusted IPI and the tumor score) in 37 patients, demonstrating that neither model selected for a group of with statistically significant differences in rates of CR, failure free survival and OS. However, in the same study a hypothetical tumor score model using the value of beta microglobulin was suggested because it was found it to be statistically significant for predicting failure free survival $^{32}$.

We are unable to comment on the relative merit of adding retuximab to $\mathrm{CHOP}$ regimens because of the limited number of patients received retuximab. Also, we are unable to estimate the benefit of combined modality treatment compared to CT only because of the limited number of patients received CT only.

\section{CONCLUSION}

In this single institute, retrospective study, we found that PMBCL patients have female predominance and young median age population. PMBCL patients have longer survival rates and plateau EFS than results of DLBCL documented in literatures. Female gender was the only factor significantly influencing the outcome of PMBCL.

\section{REFERENCES}

1. Lichtenstein AK, Levine A, Taylor CR, Boswell W, Rossman S, Feinstein DI, et al. Primary mediastinal lymphoma in adults. Am.J.Med. 1980 Apr;68(4):509-14.

2. Addis BJ, Isaacson PG. Large cell lymphoma of the mediastinum: A B-cell tumour of probable thymic origin. Histopathology 1986 Apr;10(4):379-90.

3. Aisenberg AC. Primary large cell lymphoma of the mediastinum. Semin.Oncol. 1999 Jun;26(3):251-8.

4. Todeschini G, Secchi S, Morra E, Vitolo U, Orlandi E, Pasini F, et al. Primary mediastinal large B-cell lymphoma (PMLBCL): Long-term results from a retrospective multicentre Italian experience in 138 patients treated with CHOP or MACOP-B/VACOP-B. Br.J.Cancer 2004 Jan 26;90(2):372-6.

5. Bentz M, Barth TF, Bruderlein S, Bock D, Schwerer MJ, Baudis M, et al. Gain of chromosome arm 9p is characteristic of primary Mediastinal B-cell Lymphoma (MBL): Comprehensive molecular cytogenetic analysis and presentation of a novel MBL cell line. Genes Chromosomes Cancer 2001 Apr;30(4):393-401.

6. Joos S, Otano Joos MI, Ziegler S, Bruderlein S, du Manoir S, Bentz M, et al. Primary mediastinal (thymic) B-cell lymphoma is characterized by gains of chromosomal material including 9p and amplification of the REL gene. Blood 1996 Feb 15;87(4):1571-8.

7. Lazzarino M, Orlandi E, Paulli M, Strater J, Klersy C, Gianelli U, et al. Treatment outcome and prognostic 
factors for primary mediastinal (thymic) B-cell lymphoma: A multicenter study of 106 patients. J.Clin.Oncol. 1997 Apr;15(4):1646-53.

8. Haioun C, Gaulard P, Roudot Thoraval F, Divine M, Jouault $\mathrm{H}$, Lebourgeois JP, et al. Mediastinal diffuse large-cell lymphoma with sclerosis: A condition with a poor prognosis. Am.J.Clin.Oncol. 1989 Oct;12(5): 425-9.

9. Lazzarino M, Orlandi E, Paulli M, Boveri E, Morra E, Brusamolino E, et al. Primary mediastinal B-cell lymphoma with sclerosis: An aggressive tumor with distinctive clinical and pathologic features. J.Clin.Oncol. 1993 Dec;11(12):2306-13.

10. Todeschini G, Ambrosetti A, Meneghini V, Pizzolo G, Menestrina F, Chilosi M, et al. Mediastinal large-B-cell lymphoma with sclerosis: A clinical study of 21 patients. J.Clin.Oncol. 1990 May;8(5):804-8.

11. Lavabre Bertrand T, Donadio D, Fegueux N, Jessueld D, Taib J, Charlier D, et al. A study of 15 cases of primary mediastinal lymphoma of B-cell type. Cancer 1992 May 15;69(10):2561-6.

12. Cazals Hatem D, Lepage E, Brice P, Ferrant A, d'Agay MF, Baumelou E, et al. Primary mediastinal large B-cell lymphoma. A clinicopathologic study of 141 cases compared with 916 nonmediastinal large B-cell lymphomas, a GELA ("Groupe d'Etude des Lymphomes de l'Adulte") study. Am.J.Surg.Pathol. 1996 Jul;20(7):877-88.

13. Zinzani PL, Martelli M, Magagnoli M, Pescarmona E, Scaramucci L, Palombi F, et al. Treatment and clinical management of primary mediastinal large B-cell lymphoma with sclerosis: MACOP-B regimen and mediastinal radiotherapy monitored by (67)Gallium scan in 50 patients. Blood 1999 Nov 15;94(10):3289-93.

14. Zinzani PL, Martelli M, Bertini M, Gianni AM, Devizzi $\mathrm{L}$, Federico $\mathrm{M}$, et al. Induction chemotherapy strategies for primary mediastinal large B-cell lymphoma with sclerosis: A retrospective multinational study on 426 previously untreated patients. Haematologica 2002 Dec; 87(12):1258-64.

15. Savage KJ, Al Rajhi N, Voss N, Paltiel C, Klasa R, Gascoyne RD, et al. Favorable outcome of primary mediastinal large B-cell lymphoma in a single institution: The British Columbia experience. Ann.Oncol. 2006 Jan;17(1):123-30.

16. Rosenwald A, Wright G, Leroy K, Yu X, Gaulard P, Gascoyne RD, et al. Molecular diagnosis of primary mediastinal B cell lymphoma identifies a clinically favorable subgroup of diffuse large B cell lymphoma related to Hodgkin lymphoma. J.Exp.Med. 2003 Sep 15;198(6):851-62.

17. Savage KJ, Monti S, Kutok JL, Cattoretti G, Neuberg D, De Leval L, et al. The molecular signature of mediastinal large B-cell lymphoma differs from that of other diffuse large B-cell lymphomas and shares features with classical Hodgkin lymphoma. Blood 2003 Dec 1;102(12):3871-9.

18. Harris NL, Jaffe ES, Stein H, Banks PM, Chan JK, Cleary ML, et al. A revised European-American classification of lymphoid neoplasms: A proposal from the International Lymphoma Study Group. Blood 1994 Sep 1;84(5):1361-92.

19. Banks PM, Warnke RA. Mediastinal (thymic) large B-cell lymphoma. In: Jaffe ES, Harris NL, Stein H, Vardiman JW, editors. World Health Organization classification of tumours. Pathology and genetics of tumours of haematopoietic and lymphoid tissues. Lyon: IARC Press; 2001. pp. 175-8.

20. Menestrina F, Chilosi M, Bonetti F, Lestani M, Scarpa A, Novelli P, et al. Mediastinal large-cell lymphoma of B-type, with sclerosis: Histopathological and immunohistochemical study of eight cases. Histopathology 1986 Jun; 10(6):589-600.

21. Perrone T, Frizzera G, Rosai J. Mediastinal diffuse largecell lymphoma with sclerosis. A clinicopathologic study of 60 cases. Am.J.Surg.Pathol. 1986 Mar;10(3):176-91.

22. Strickler JG, Kurtin PJ. Mediastinal lymphoma. Semin. Diagn.Pathol. 1991 Feb;8(1):2-13.

23. Jacobson JO, Aisenberg AC, Lamarre L, Willett CG, Linggood RM, Miketic LM, et al. Mediastinal large cell lymphoma. An uncommon subset of adult lymphoma curable with combined modality therapy. Cancer 1988 Nov. 1;62(9):1893-8.

24. Andreopoulou E, Pectasides D, Dimopoulos MA, Nikolaides C, Fountzilas G, Valsami S, et al. Primary mediastinal large B-cell lymphoma: Clinical study of a distinct clinical entity and treatment outcome in 20 patients: Review of the literature. Am.J.Clin.Oncol. 2004 Jun;27(3):312-6.

25. Bertini M, Orsucci L, Vitolo U, Levis A, Todeschini G, Meneghini V, et al. Stage II large B-cell lymphoma with sclerosis treated with MACOP-B. Ann.Oncol. 1991 NovDec;2(10):733-7.

26. Kirn D, Mauch P, Shaffer K, Pinkus G, Shipp MA, Kaplan WD, et al. Large-cell and immunoblastic lymphoma of the mediastinum: Prognostic features and treatment outcome in 57 patients. J.Clin.Oncol. 1993 Jul;11(7):1336-43.

27. Nguyen LN, Ha CS, Hess M, Romaguera JE, Manning JT, Cabanillas F, et al. The outcome of combinedmodality treatments for stage I and II primary large B-cell lymphoma of the mediastinum. Int.J.Radiat.Oncol.Biol. Phys. 2000 Jul 15;47(5):1281-5.

28. Chim CS, Liang R, Chan AC, Kwong YL, Ho FC, Todd D. Primary B cell lymphoma of the mediastinum. Hematol. Oncol. 1996 Dec;14(4):173-9.

29. Mazzarotto R, Boso C, Vianello F, Aversa MS, Chiarion Sileni V, Trentin L, et al. Primary mediastinal large B-cell lymphoma: Results of intensive chemotherapy regimens (MACOP-B/VACOP-B) plus involved field radiotherapy on 53 patients. A single institution experience. Int.J.Radiat. Oncol.Biol.Phys. 2007 Jul 1;68(3):823-9.

30. Hamlin PA, Portlock CS, Straus DJ, Noy A, Singer A, Horwitz SM, et al. Primary mediastinal large B-cell lymphoma: Optimal therapy and prognostic factor analysis in 141 consecutive patients treated at Memorial Sloan Kettering from 1980 to 1999. Br.J.Haematol. 2005 Sep;130(5):691-9. 
31. Fisher RI, Gaynor ER, Dahlberg S, Oken MM, Grogan TM, Mize EM, et al. Comparison of a standard regimen (CHOP) with three intensive chemotherapy regimens for advanced non-Hodgkin's lymphoma. N.Engl.J.Med. 1993 Apr 8;328(14):1002-6.

32. Romaguera JE, Rodriguez Diaz Pavon J, Carias L,
Hagemeister FB, McLaughlin P, Rodriguez MA, et al. Use of the international prognostic index and the tumor score to detect poor-risk patients with primary mediastinal large B-cell lymphoma: A study of 37 previously untreated patients. Leuk.Lymphoma 1998 Jan;28(3-4):295-306. 